\title{
Topoisomerase Mutations That Are Associated with High-Level Resistance to Earlier Fluoroquinolones in Staphylococcus aureus Have Less Effect on the Antibacterial Activity of Besifloxacin
}

\author{
Christine M. Sanfilippo Christine K. Hesje Wolfgang Haas Timothy W. Morris \\ Bausch \& Lomb, Inc., Rochester, N.Y., USA
}

Key Words

Besifloxacin - Fluoroquinolones - Staphylococcus aureus .

Topoisomerase mutations

\begin{abstract}
Background: The impact of mutations in DNA gyrase and topoisomerase IV on minimum inhibitory concentrations (MICs) was investigated to better understand why besifloxacin has a higher potency against Staphylococcus aureus when compared to other fluoroquinolones, which was especially pronounced against ciprofloxacin-resistant isolates. Methods: MICs were determined for 52 clinical isolates against besifloxacin, moxifloxacin, gatifloxacin, ciprofloxacin, and levofloxacin. The genes encoding GyrA, GyrB, ParC, and ParE were sequenced and the potential impact of mutations assessed in light of recent structural data. Results: For all fluoroquinolones tested, the MICs increased with the number of mutations in the quinolone resistance-determining regions. However, this increase was the smallest for besifloxacin and the largest for ciprofloxacin and levofloxacin. In addition to the commonly observed mutations in ParC and GyrA, more unusual mutations in ParE, such as Asp-432 $\rightarrow$ His or Pro$585 \rightarrow$ Ser, were also detected. Conclusions: Compared to earlier fluoroquinolones, the higher potency of besifloxacin suggests that the drug's unique combination of a 7-azepinyl ring and an 8-chloro-substituent results in unique interactions with DNA gyrase and topoisomerase IV.
\end{abstract}

Copyright $\odot 2011$ S. Karger AG, Basel

\section{KARGER}

Fax +4161306 1234 E-Mail karger@karger.ch www.karger.com

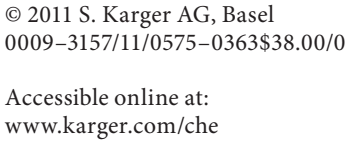

\section{Introduction}

Staphylococcus aureus is an important nosocomial and community-acquired pathogen which can cause mild to life-threatening diseases in humans, including infections of the eye. Topical ophthalmic antimicrobial agents, including those belonging to the fluoroquinolone and macrolide classes of compounds, are commonly used for the treatment of ocular infections. The increasing resistance of $S$. aureus to many drug classes, including fluoroquinolones, has resulted in the emergence of multidrug-resistant strains, emphasizing the need for new antimicrobial agents. Besifloxacin is a novel 7-azepinyl8-chloro-fluoroquinolone that has shown improved in vitro potency as well as clinical efficacy against numerous ophthalmic pathogens [1-4]. It has recently been approved in the United States as besifloxacin ophthalmic suspension, $0.6 \%$ (Besivance ${ }^{\circledR}$ ) for the topical treatment of bacterial conjunctivitis.

Mutations in the genes encoding the essential enzymes DNA gyrase and topoisomerase IV are the primary cause of clinically relevant levels of fluoroquinolone resistance in S. aureus $[5,6]$, although efflux pumps such as NorA or MepA also contribute [7-9]. DNA gyrase is responsible for maintaining negative supercoiling of bacterial chromosomes and is composed of two subunits, GyrA and GyrB. The function of topoisomerase IV is essential for decatenation of interlinked bacterial chromosomes after replica-

Christine M. Sanfilippo

1400 N. Goodman St.

Rochester, NY 14609 (USA)

Tel. +1 5853386527

E-Mail christine.sanfilippo@bausch.com 
tion. Topoisomerase IV is composed of two subunits, $\mathrm{ParC}$ and ParE (also known as GrlA and GrlB, respectively). DNA gyrase and topoisomerase IV are very similar to each other in sequence, structure, and function. Both enzymes bind to DNA, induce a double-strand break, pass a second strand of duplex DNA through the breech, and re-ligate the broken DNA strand [10]. The addition of a fluoroquinolone traps the drug, the enzyme, and the cleaved DNA in a ternary cleavage complex that ultimately results in the death of the cell [10]. Fluoroquinolone treatment leads to the selection of strains that contain mutations in DNA gyrase and topoisomerase IV. Mutations that confer high-level fluoroquinolone resistance are frequently found in 'hot spot' regions of GyrA, GyrB, ParC, and ParE termed the quinolone resistance-determining region (QRDR) $[11,12]$.

Recent work $[4,13]$ has shown that besifloxacin has the lowest minimum inhibitory concentration (MIC) values for $S$. aureus when compared to earlier fluoroquinolones, such as moxifloxacin, gatifloxacin, ciprofloxacin, or levofloxacin. Moreover, biochemical studies with purified Streptococcus pneumoniae DNA gyrase and topoisomerase IV showed that besifloxacin had a higher affinity for both enzymes than moxifloxacin and ciprofloxacin [14]. While the differences in potency between besifloxacin and the comparators were noticeable among all $S$. aureus isolates, they were especially pronounced in fluoroquinolone-resistant strains. In order to investigate the differential impact of mutations in DNA gyrase and topoisomerase IV on MIC values for besifloxacin and other fluoroquinolones, we sequenced the $g y r A$, $g y r B$, parC, and parE genes in their entire length and determined MIC values for besifloxacin, moxifloxacin, gatifloxacin, ciprofloxacin, and levofloxacin. The results are discussed in light of the recently published structural analyses of fluoroquinolone-DNA complexes with DNA gyrase or topoisomerase IV [15-17].

\section{Materials and Methods}

\section{Bacterial Strains and Growth Conditions}

Fifty-two recently isolated (from 2005 to 2008) ocular S. aureus strains, which were either fluoroquinolone-susceptible ( $\mathrm{n}=$ 13) or fluoroquinolone-resistant $(n=39)$, were obtained from $\mathrm{Eu}$ rofins Medinet (Chantilly, Va., USA). Fluoroquinolone resistance was defined by the Clinical Laboratory and Standards Institute (CLSI) breakpoint for ciprofloxacin as a MIC of $\geq 4 \mu \mathrm{g} / \mathrm{ml}$ [18]. $S$. aureus ATCC 29213 (American Type Culture Collection, Manassas, Va., USA) was included in all assays as a quality control strain. Unless noted otherwise, all strains were grown in Tryptic Soy Broth (Difco Laboratories, Detroit, Mich., USA) for $18-24$ h at $37^{\circ} \mathrm{C}$ under ambient conditions.
Antimicrobial Agents and Antimicrobial Susceptibility Testing Besifloxacin (Bausch \& Lomb, Rochester, N.Y., USA), moxifloxacin, gatifloxacin, ciprofloxacin, and levofloxacin (LKT Laboratories, St. Paul, Minn., USA) were solubilized and diluted as recommended by the manufacturers.

MIC testing was performed by the broth microdilution method in accordance with CLSI guidelines [19]. All experiments were performed in triplicate; for each strain, modal or, when modal values could not be defined, central MIC values are reported here.

To test for the possible effect of efflux pumps on fluoroquinolone MIC values, MIC testing was performed for besifloxacin, moxifloxacin, gatifloxacin, ciprofloxacin, levofloxacin, and ethidium bromide (EMD Chemicals, Gibbstown, N.J., USA) against all isolates in the presence or absence of $20 \mu \mathrm{g} / \mathrm{ml}$ of the efflux pump inhibitor reserpine (SPEX CertiPrep, Metuchen, N.J., USA).

PCR Amplification and Sequence Analysis

Genomic DNA was extracted from pure bacterial cultures using the Wizard Genomic DNA Purification Kit (Promega, Madison, Wisc., USA) and was used as the template for PCR amplification. The complete gyrA, gyrB, parC, and parE genes from each isolate were amplified using the oligonucleotide primers listed in the supplementary material (online suppl. table 1; for all online supplementary material, see www.karger.com/doi/10.1159/000330858). The sequence used for primer design was the published complete genome of $S$. aureus strain Newman (GenBank accession No. NC_009641).

PCR reactions were carried out in a MyCycler thermal cycler (BioRad, Hercules, Calif., USA) in a 100- $\mu$ l volume containing 0.4 $\mu \mathrm{M}$ primers (Integrated DNA Technologies, Coralville, Iowa, USA), $200 \mu \mathrm{M}$ deoxynucleoside triphosphates (Omega Bio-Tek, Norcross, Ga., USA), 1 U of Vent DNA polymerase and its reaction buffer containing $2 \mathrm{mM}$ magnesium sulfate (New England Biolabs, Ipswich, Mass., USA). The initial cycle of denaturation (10 min at $94^{\circ} \mathrm{C}$ ) preceded $30-33$ cycles consisting of 0.5 min of denaturation at $94^{\circ} \mathrm{C}, 0.5-1 \mathrm{~min}$ of annealing at 57 or $59^{\circ} \mathrm{C}$, and 1 min of elongation at $72^{\circ} \mathrm{C}$, and was followed by a final cycle of elongation $\left(10 \mathrm{~min}\right.$ at $\left.72^{\circ} \mathrm{C}\right)$. PCR products were purified using the QIAquick PCR Purification Kit (Qiagen, Valencia, Calif., USA) or the EZNA Cycle Pure Kit (Omega Bio-Tek), and sequenced by ACGT Inc. (Wheeling, Ill., USA) or Macrogen USA (Rockville, Md., USA).

Clone Manager 9 analysis software (Sci-Ed Software, Cary, N.C., USA) was used for primer design and sequence analyses. In this study, the QRDR for each protein was defined as follows: GyrA: residues 68-107; GyrB: residues 432-458; ParC: residues 64-116, and ParE: residues 432-470 (numbering based on $S$. aureus NCTC8325, GenBank accession No. NC_007795). Sequence and MIC data for individual strains are available online as supplemental information (online suppl. tables S2-S7).

Structure-Function Evaluation

The data obtained here were compared to various crystal structures of truncated and otherwise modified DNA gyrase or topoisomerase IV in complex with DNA and a fluoroquinolone. Laponogov et al. [15] published the structure of the DNA cleavage complex formed by topoisomerase IV from S. pneumoniae stabilized by DNA and moxifloxacin (Protein Data Bank accession 
code 3FOF). Wohlkonig et al. [16] published the structure of topoisomerase IV from Acinetobacter baumannii complexed with DNA and moxifloxacin, while Bax et al. [17] reported the structure of DNA gyrase from $S$. aureus bound to DNA and ciprofloxacin (Protein Data Bank accession codes 2XKK and 2XCT, respectively).

\section{Results and Discussion}

\section{Cumulative MIC Values of S. aureus Isolates}

Figure 1 shows the cumulative MIC values for the 14 (26.4\%) fluoroquinolone-susceptible and 39 (73.6\%) ciprofloxacin-resistant isolates of $S$. aureus for the five fluoroquinolones tested in this study. Overall, besifloxacin was the most potent agent, followed by moxifloxacin and gatifloxacin, which had similar activity profiles. Among the least potent drugs, levofloxacin was more active than ciprofloxacin against fluoroquinolone-susceptible and most of the fluoroquinolone-resistant isolates. However, against the most resistant isolates, ciprofloxacin was more active than levofloxacin.

Interestingly, the gap between the most and the least potent fluoroquinolones widened with increasing resistance of the isolates. For example, the minimum MIC values $(\mu \mathrm{g} / \mathrm{ml})$ were 0.015 for besifloxacin and 0.12 for ciprofloxacin and levofloxacin, representing an 8-fold difference in potency. In contrast, the maximum MIC values $(\mu \mathrm{g} / \mathrm{ml})$ were 8 for besifloxacin and 1,024 for levofloxacin, which is a 128 -fold difference. Similar trends were observed for all isolates and fluoroquinolones.

\section{Mutations in Fluoroquinolone-Susceptible Strains}

To gain further insights into the effect that mutations in DNA gyrase and topoisomerase IV have on fluoroquinolone MIC values, the $g y r A, \operatorname{gyrB}$, parC, and parE genes of 13 clinical, fluoroquinolone-susceptible isolates and the quality control strain ATCC 29213 were sequenced and compared to the sequences obtained from seven $S$. aureus genomes of fluoroquinolone-susceptible isolates. In order to differentiate between mutations that potentially contribute to fluoroquinolone resistance and those that might not, it was important to assess the degree of amino acid variation that occurs in fluoroquinolone-susceptible isolates. Table 1 shows all amino acid substitutions or deletions in GyrA, GyrB, ParC, and ParE that were observed in these 21 fluoroquinolone-susceptible $S$. aureus strains. None of these mutations in fluoroquinolone-susceptible strains were located within the QRDRs of DNA gyrase or topoisomerase IV.

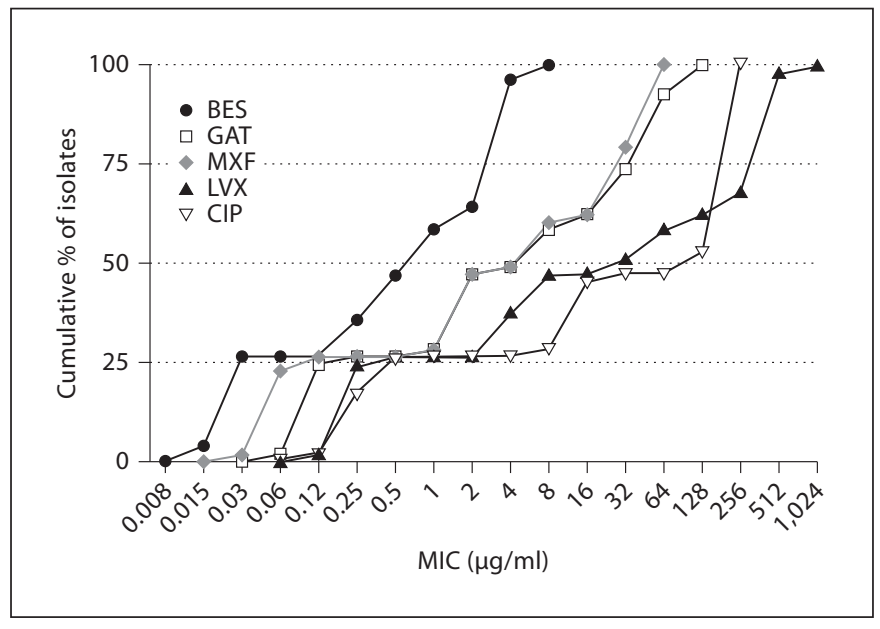

Fig. 1. Cumulative MIC values for 14 (26.4\%) fluoroquinolonesusceptible and 39 (73.6\%) fluoroquinolone-resistant isolates of $S$. aureus against besifloxacin (BES), gatifloxacin (GAT), moxifloxacin (MXF), levofloxacin (LVX), and ciprofloxacin (CIP).

Table 1. Amino acid variations in DNA gyrase and topoisomerase IV sequences from 21 fluoroquinolone-susceptible strains

\begin{tabular}{|c|c|}
\hline Protein & Amino acid \\
\hline GyrA & $\begin{array}{l}\text { Val-248 } \rightarrow \text { Glu, Gly- } 255 \rightarrow \text { Arg, Ala- } 457 \rightarrow \text { Thr, } \\
\text { Asp- } 483 \rightarrow \text { Glu, Asp- } 495 \rightarrow \text { Asn, Glu- } 594 \rightarrow \text { Gly, } \\
\text { Val-598 } \rightarrow \text { Ile, Ser- } 668 \rightarrow \text { Ala, Val-712 } \rightarrow \text { Ile, } \\
\text { Glu-815 } \rightarrow \Delta, \text { Thr-818 } \rightarrow \text { Val, Ser-826 } \rightarrow \Delta, \\
\text { Thr-827 } \rightarrow \Delta \text {, Arg-837 } \rightarrow \text { His, Asp-856 } \rightarrow \text { Glu, } \\
\text { Asn-860 } \rightarrow \text { Thr, Glu-886 } \rightarrow \text { Asp }\end{array}$ \\
\hline GyrB & $\begin{array}{l}\text { Val-28 } \rightarrow \text { Ala, Gln- } 66 \rightarrow \text { Lys, Glu-317 } \rightarrow \text { Asp, } \\
\text { Gly- } 491 \rightarrow \text { Asp, Glu- } 568 \rightarrow \text { Lys }\end{array}$ \\
\hline ParC & $\begin{array}{l}\text { Ile- } 45 \rightarrow \text { Met, Pro- } 144 \rightarrow \text { Ser, Ile- } 223 \rightarrow \text { Val, } \\
\text { Ser- } 267 \rightarrow \text { Gly, Arg- } 372 \rightarrow \text { His, Arg- } 400 \rightarrow \text { Cys, } \\
\text { Glu- } 404 \rightarrow \text { Gly, Tyr- } 410 \rightarrow \text { Phe, Phe- } 521 \rightarrow \text { Tyr, } \\
\text { Phe-594 } \rightarrow \text { Tyr, Asp- } 641 \rightarrow \text { Asn, Lys- } 650 \rightarrow \text { Arg, } \\
\text { Val-656 } \rightarrow \text { Ile, Ala- } 688 \rightarrow \text { Val, Met- } 694 \rightarrow \text { Val }\end{array}$ \\
\hline ParE & $\begin{array}{l}\text { Gly- } 107 \rightarrow \text { Ser, Asn- } 139 \rightarrow \text { Ser, Ser- } 230 \rightarrow \text { Gly, } \\
\text { Val-327 } \rightarrow \text { Ile, Glu- } 422 \rightarrow \text { Asp, His- } 478 \rightarrow \text { Tyr } \\
\text { Gly- } 530 \rightarrow \text { Asp, Glu- } 596 \rightarrow \text { Asp, Val- } 609 \rightarrow \text { Leu }\end{array}$ \\
\hline
\end{tabular}

The DNA gyrase and topoisomerase IV genes from ATCC 29213 and 13 clinical isolates were sequenced for this study. Sequence information from 7 other fluoroquinolone-susceptible strains was obtained from GenBank: Newman (NC_009641), N315 (NC_002745), NCTC8325 (NC_007795), RF122 (NC_007622), MSSA476 (NC_002953), COL (NC_002951), and MW2 (NC_003923).

$\Delta=$ Amino acid deletion. 
Table 2. DNA gyrase and topoisomerase IV mutations and MIC distribution of 53 S. aureus isolates

\begin{tabular}{|c|c|c|c|c|c|c|c|c|c|c|c|c|c|c|c|c|c|c|c|}
\hline \multirow{2}{*}{$\begin{array}{l}\text { Mutant group and } \\
\text { number of isolates }\end{array}$} & \multirow{2}{*}{$\begin{array}{l}\text { QRDR mutations } \\
\text { per group }\end{array}$} & \multirow[t]{2}{*}{ Drug } & \multicolumn{17}{|c|}{ Number of isolates per MIC $(\mu \mathrm{g} / \mathrm{ml})$} \\
\hline & & & 0.015 & 0.03 & 0.06 & 0.12 & 0.25 & 0.5 & 1 & 2 & 4 & 8 & 16 & 32 & 64 & 128 & 256 & 512 & 1,024 \\
\hline \multirow{5}{*}{$\begin{array}{l}\text { Group } 1^{\mathrm{a}} \\
(\mathrm{n}=14)\end{array}$} & \multirow[t]{5}{*}{ none } & BES & 2 & 12 & & & & & & & & & & & & & & & \\
\hline & & $\overline{\mathrm{MXF}}$ & & 1 & 11 & 2 & & & & & & & & & & & & & \\
\hline & & $\overline{\mathrm{GAT}}$ & & & 1 & 12 & 1 & & & & & & & & & & & & \\
\hline & & $\overline{\mathrm{CIP}}$ & & & & 1 & 8 & 5 & & & & & & & & & & & \\
\hline & & $\overline{\mathrm{LVX}}$ & & & & 1 & 12 & 1 & & & & & & & & & & & \\
\hline \multirow{5}{*}{$\begin{array}{l}\text { Group 2 } \\
(\mathrm{n}=12)\end{array}$} & \multirow{5}{*}{$\begin{array}{l}\text { GyrA (Ser-84 } \rightarrow \text { Leu }) \\
\text { ParC (Ser-80 } \rightarrow \text { Tyr/Phe) }\end{array}$} & BES & & & & & 5 & 6 & $1^{\mathrm{b}}$ & & & & & & & & & & \\
\hline & & $\overline{\mathrm{MXF}}$ & & & & & & & 1 & 10 & $1^{\mathrm{b}}$ & & & & & & & & \\
\hline & & $\overline{\mathrm{GAT}}$ & & & & & & & 1 & 10 & & $1^{\mathrm{b}}$ & & & & & & & \\
\hline & & $\overline{\mathrm{CIP}}$ & & & & & & & & & & 1 & 9 & 1 & & & $1^{\mathrm{b}}$ & & \\
\hline & & $\overline{\mathrm{LVX}}$ & & & & & & & & & 6 & 5 & & $1^{\mathrm{b}}$ & & & & & \\
\hline \multirow{5}{*}{$\begin{array}{l}\text { Group } 3 \\
(\mathrm{n}=6)\end{array}$} & \multirow{5}{*}{$\begin{array}{l}\text { GyrA (Ser-84 } \rightarrow \text { Leu }) \\
\text { ParC (Ser-80 } \rightarrow \text { Tyr }) \\
\text { ParC (Glu- } 84 \rightarrow \text { Gly })\end{array}$} & BES & & & & & & & 5 & 1 & & & & & & & & & \\
\hline & & $\overline{\mathrm{MXF}}$ & & & & & & & & & & 5 & 1 & & & & & & \\
\hline & & $\overline{\mathrm{GAT}}$ & & & & & & & & & 1 & 4 & 1 & & & & & & \\
\hline & & $\overline{\mathrm{CIP}}$ & & & & & & & & & & & & & & & 6 & & \\
\hline & & $\overline{\mathrm{LVX}}$ & & & & & & & & & & & & 1 & 4 & 1 & & & \\
\hline \multirow{5}{*}{$\begin{array}{l}\text { Group } 4 \\
(\mathrm{n}=3)\end{array}$} & \multirow{5}{*}{$\begin{array}{l}\text { GyrA (Ser-84 } \rightarrow \text { Leu }) \\
\text { GyrA (Ser-85 } \rightarrow \text { Pro }) \\
\text { ParC (Ser-80 } \rightarrow \text { Phe/Tyr) } \\
\text { ParE (Asp-432 } \rightarrow \text { His/Asn })\end{array}$} & BES & & & & & & & & & 3 & & & & & & & & \\
\hline & & MXF & & & & & & & & & & $1^{\mathrm{c}}$ & & 1 & 1 & & & & \\
\hline & & GAT & & & & & & & & & & & $1^{\mathrm{c}}$ & 2 & & & & & \\
\hline & & $\overline{\mathrm{CIP}}$ & & & & & & & & & & & & & & 3 & & & \\
\hline & & $\overline{\mathrm{LVX}}$ & & & & & & & & & & & & & & $1^{c}$ & & 2 & \\
\hline \multirow{5}{*}{$\begin{array}{l}\text { Group } 5 \\
(\mathrm{n}=10)\end{array}$} & \multirow{5}{*}{$\begin{array}{l}\text { GyrA (Ser-84 } \rightarrow \text { Leu) } \\
\text { GyrA (Ser-85 } \rightarrow \text { Pro) } \\
\text { ParC (Ser-80 } \rightarrow \text { Tyr) } \\
\text { ParC (Glu- } 84 \rightarrow \text { Gly) }\end{array}$} & BES & & & & & & & & & 10 & & & & & & & & \\
\hline & & MXF & & & & & & & & & & & & 5 & 5 & & & & \\
\hline & & $\overline{\text { GAT }}$ & & & & & & & & & & & & 1 & 9 & & & & \\
\hline & & $\overline{\mathrm{CIP}}$ & & & & & & & & & & & & & & & 10 & & \\
\hline & & $\overline{\mathrm{LVX}}$ & & & & & & & & & & & & & & & & 9 & 1 \\
\hline \multirow{5}{*}{$\begin{array}{l}\text { Group } 6 \\
(\mathrm{n}=8)\end{array}$} & \multirow{5}{*}{$\begin{array}{l}\text { GyrA (Ser-84 } \rightarrow \text { Leu }) \\
\text { GyrA (Glu- } 88 \rightarrow \text { Lys/Ala) } \\
\text { ParC (Ser-80 } \rightarrow \text { Tyr) } \\
\text { ParC (Glu- } 84 \rightarrow \text { Gly) }\end{array}$} & BES & & & & & & & & 2 & 4 & 2 & & & & & & & \\
\hline & & MXF & & & & & & & & & & & & 3 & 5 & & & & \\
\hline & & GAT & & & & & & & & & & & & 3 & 1 & 4 & & & \\
\hline & & $\mathrm{CIP}$ & & & & & & & & & & & & & & & 8 & & \\
\hline & & $\overline{\mathrm{LVX}}$ & & & & & & & & & & & & & & & 3 & 5 & \\
\hline
\end{tabular}

BES = Besifloxacin; MXF = moxifloxacin; GAT = gatifloxacin; CIP = ciprofloxacin; LVX = levofloxacin.

${ }^{a}$ Includes 13 clinical isolates and laboratory control strain ATCC 29213. ${ }^{\text {b }}$ One isolate in Group 2 carried an additional non-QRDR Pro-585 $\rightarrow$ Ser mutation in ParE. ${ }^{c}$ One isolate in Group 4 carried the Asp- $432 \rightarrow$ Asn mutation in ParE.

\section{MIC Distributions in Groups 1-6}

Based on the QRDR mutations present in their DNA gyrase and topoisomerase IV, isolates were placed into 6 groups (table 2). Group $1(\mathrm{n}=14)$ lacked QRDR mutations and contained only fluoroquinolone-susceptible isolates. Modal MIC values $(\mu \mathrm{g} / \mathrm{ml})$ were 0.03 for besifloxacin, 0.06 for moxifloxacin, 0.12 for gatifloxacin, and 0.25 for ciprofloxacin and levofloxacin. Outlying MIC values differed by no more than one 2 -fold dilution above or below these modal values.

The 12 strains in Group 2 all contained 1 mutation in GyrA (Ser-84 $\rightarrow$ Leu) as well as 1 in ParC (Ser-80 $\rightarrow$ Tyr/ Phe). All but one isolate in this group had MIC values $(\mu \mathrm{g} / \mathrm{ml})$ of $0.25-0.5$ for besifloxacin, 1-2 for moxifloxacin and gatifloxacin, 4-8 for levofloxacin, and 8-32 for ciprofloxacin. The one notable exception was a strain that contained a Pro-585 $\rightarrow$ Ser non-QRDR mutation in the ParE protein. This strain had, depending on the fluoroquinolone tested, 2- to 32-fold higher MIC values when compared to other strains in the same group. Efflux pumps inhibitors (reserpine, carbonyl cyanide mchlorophenyl hydrazone [CCCP], and sodium orthovanadate) did not affect this strain more than any other strain that we tested (data not shown). The potential role of the Pro-585 residue might instead be in modulating dimer-dimer interactions (see discussion below). 
Fig. 2. General structure of fluoroquinolones and structures of those fluoroquinolones used in this study.<smiles>[R8]c1c(F)cc2c(=O)c(C(=O)O)cn([R1])c2c1[R8]</smiles>

Fluoroquinolone

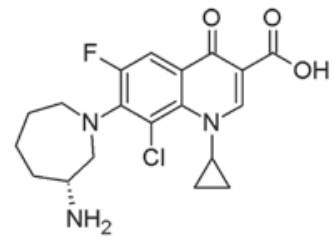

Besifloxacin

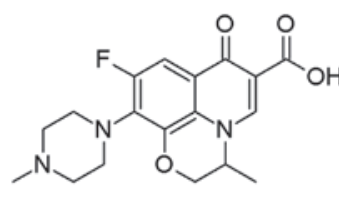

Levofloxacin<smiles>O=C(O)c1cn(C2CC2)c2cc(N3CCNCC3)c(F)cc2c1=O</smiles>

Ciprofloxacin

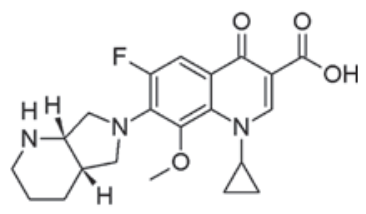

Moxifloxacin
All 6 isolates in Group 3 had in common 1 mutation in GyrA (Ser-84 $\rightarrow$ Leu) plus 2 mutations in ParC (Ser$80 \rightarrow$ Tyr, Glu- $84 \rightarrow$ Gly). Modal MIC values $(\mu \mathrm{g} / \mathrm{ml})$ were 1 for besifloxacin, 8 for moxifloxacin and gatifloxacin, 64 for levofloxacin, and 256 for ciprofloxacin. As in Group 2 , but unlike the other 4 groups, levofloxacin was more potent than ciprofloxacin in Group 3. Isolates in Group 2 and Group 3 differed in their ParC mutations, but had in common that they contained only 1 Ser-84 $\rightarrow$ Leu mutation in GyrA. It is of interest to note that an additional mutation in GyrA, as seen in Groups 5 and 6, did not increase the ciprofloxacin MIC values, but increased the MIC values of the other fluoroquinolones. Ciprofloxacin is similar to besifloxacin, moxifloxacin, and gatifloxacin in that it contains a cyclopropyl ring at R1, while the 7-piperazinyl group is structurally similar to the 7-methylpiperazinyl groups found in levofloxacin and gatifloxacin (fig. 2). However, unlike the other fluoroquinolones tested here, ciprofloxacin does not possess any R8 substituents, which have been shown to increase the antibacterial potency of fluoroquinolones against $S$. aureus [20]. This difference in chemical structure might explain why ciprofloxacin is less potent than levofloxacin against the mutant strains in Groups 2 and 3.

Group 4 consisted of 3 isolates that had in common GyrA (Ser-84 $\rightarrow$ Leu, Ser-85 $\rightarrow$ Pro) and ParC (Ser-80 $\rightarrow$ Phe/Tyr) mutations and that also contained an Asp-432 $\rightarrow$ His/Asn mutation in the QRDR of ParE. While the MIC values $(\mu \mathrm{g} / \mathrm{ml})$ for all 3 isolates were 4 for besifloxacin and 128 for ciprofloxacin, the MIC values for the other fluoroquinolones were spread out over a wider range:
8-64 for moxifloxacin, 16-32 for gatifloxacin, and 128512 for levofloxacin. The one strain carrying the Asp$432 \rightarrow$ Asn mutation in ParE had the lowest MIC values when compared to the other two strains that contained the Asp-432 $\rightarrow$ His mutation in ParE.

Ten isolates made up Group 5, all of which contained 2 mutations each in GyrA (Ser-84 $\rightarrow$ Leu, Ser- $85 \rightarrow$ Pro) and ParC (Ser-80 $\rightarrow$ Tyr, Glu- $84 \rightarrow$ Gly). MIC values $(\mu \mathrm{g} /$ $\mathrm{ml}$ ) for almost all isolates were 4 for besifloxacin, 32-64 for moxifloxacin, 64 for gatifloxacin, 256 for ciprofloxacin, and 512 for levofloxacin. The MIC values for the two outliers differed by only one serial dilution from the modal values.

Isolates in Group $6(\mathrm{n}=8)$ had similar mutations as those in Group 5, except that they contained a Glu$88 \rightarrow$ Lys/Ala mutation in GyrA instead of the Ser- $85 \rightarrow$ Pro mutation. MIC values $(\mu \mathrm{g} / \mathrm{ml})$ were also similar, although the range was wider: 2-8 for besifloxacin, 32-64 for moxifloxacin, 32-128 for gatifloxacin, 256 for ciprofloxacin, and 256-512 for levofloxacin.

All of the fluoroquinolone-resistant isolates in this study contained 2-4 mutations in the QRDRs; however, even the highly resistant isolates in Groups 4-6 contained no more than 4 QRDR mutations. All strains with 4 QRDR mutations contained the Ser-84 $\rightarrow$ Leu mutation in GyrA and the Ser- $80 \rightarrow$ Tyr/Phe mutation in ParC, 1 additional mutation in GyrA (Ser-85 $\rightarrow$ Pro or Glu-88 $\rightarrow$ Lys/ Ala) and 1 mutation in either ParC (Glu-84 $\rightarrow$ Gly) or in ParE (Asp-432 $\rightarrow$ His/Asn). Except for the one strain with the Asp-432 $\rightarrow$ Asn mutation in ParE, all isolates in Groups 4-6 had similar MIC ranges $(\mu \mathrm{g} / \mathrm{ml})$ for besifloxacin (2- 
8), moxifloxacin (32-64), gatifloxacin (32-128), ciprofloxacin (128-256) and levofloxacin (256-1,024). It would be of interest in future studies to determine if strains with 5 or more QRDR mutations are viable and have higher MIC values than those reported here.

\section{Mutations of Unknown Significance in Fluoroquinolone-Resistant Strains}

Amino acids within the QRDR, such as Ser-84 in GyrA or Ser-80 in ParC, have been shown to play a role in fluoroquinolone resistance $[5,11,12,21]$. However, residues outside the QRDR might also directly or indirectly contribute to resistance. For example, the strain carrying the Pro-585 $\rightarrow$ Ser mutation in ParE had 2 - to 16 -fold higher MIC values than other isolates in Group 2, including strains that had otherwise identical GyrA, GyrB, ParC, and ParE sequences.

Other sequence variations that were observed in the 39 fluoroquinolone-resistant isolates include mutations in GyrA (Glu-275 $\rightarrow$ Asp, Thr-325 $\rightarrow$ Ile, Asp-402 $\rightarrow$ Glu, Thr $818 \rightarrow$ Glu, Glu-859 $\rightarrow$ Val), GyrB $($ Asp-169 $\rightarrow$ His $)$, ParC (Ser-320 $\rightarrow$ Phe, Ala-402 $\rightarrow$ Val, Glu-437 $\rightarrow$ Asp), and in ParE (Ile-70 $\rightarrow$ Thr, Pro-330 $\rightarrow$ Ser). Unlike the Pro$585 \rightarrow$ Ser mutation in ParE, none of these other mutations was associated with a $\geq 4$-fold increase in MIC values. The only exception was one strain in Group 4 with an Asp-432 $\rightarrow$ Asn mutation in the QRDR of ParE; this strain also contained non-QRDR mutations in GyrA (i.e. Asp-402 $\rightarrow$ Glu, Thr-818 $\rightarrow$ Glu, and Glu-859 $\rightarrow$ Val). However, unlike the non-QRDR mutations, only the Asp-432 mutations in ParE have been shown previously to increase fluoroquinolone resistance [22-25]. Therefore, the data presented here suggest that none of the non-QRDR mutations listed above, other than the Pro-585 $\rightarrow$ Ser mutation in ParE, contribute to a fluoroquinolone-resistant phenotype.

\section{The Role of Efflux Pumps in Fluoroquinolone}

Resistance

Since efflux pumps, such as NorA, have also been implicated in resistance of $S$. aureus to fluoroquinolones [5, $21,26]$, we tested the effect of the efflux pump inhibitor reserpine on fluoroquinolone susceptibility. Table 3 shows that, for most of the isolates tested, the addition of reserpine did not substantially change the MIC values for besifloxacin, moxifloxacin, gatifloxacin, or levofloxacin. Two-fold increases or decreases in MIC values were considered to be within the experimental error of this assay. However, 12 of the 14 fluoroquinolone-susceptible isolates (Group 1) were 4 -fold more susceptible to ciproflox-
Table 3. Contribution of reserpine-susceptible efflux pumps to fluoroquinolone MIC values

\begin{tabular}{|c|c|c|c|c|c|c|}
\hline \multirow{3}{*}{$\begin{array}{l}\text { Mutant group } \\
\text { and number of } \\
\text { isolates }\end{array}$} & \multirow[t]{3}{*}{ Drug } & \multicolumn{5}{|c|}{$\begin{array}{l}\text { Number of isolates with } \mathrm{x} \text {-fold change } \\
\text { in MIC in response to reserpine }\end{array}$} \\
\hline & & \multicolumn{3}{|c|}{ decrease } & \multirow{2}{*}{$\begin{array}{l}\text { no } \\
\text { change }\end{array}$} & \multirow{2}{*}{$\begin{array}{l}\text { increase } \\
2 \times\end{array}$} \\
\hline & & & $8>$ & $4 \times 2 \times$ & & \\
\hline \multirow{6}{*}{$\begin{array}{l}\text { Fluoroquinolone- } \\
\text { susceptible isolates, } \\
\text { Group } 1 \\
(\mathrm{n}=14)\end{array}$} & BES & & & 5 & 9 & \\
\hline & MXF & & & & 8 & 6 \\
\hline & GAT & & & 1 & 12 & 1 \\
\hline & $\overline{\mathrm{LVX}}$ & & & 4 & 10 & \\
\hline & CIP & & & $12 \quad 2$ & & \\
\hline & EtBr & 5 & 8 & 1 & & \\
\hline \multirow{6}{*}{$\begin{array}{l}\text { Fluoroquinolone- } \\
\text { resistant } \\
\text { isolates, } \\
\text { Groups } 2-6 \\
(\mathrm{n}=39)\end{array}$} & BES & & & 14 & 24 & 1 \\
\hline & MXF & & & 4 & 30 & 5 \\
\hline & $\overline{\mathrm{GAT}}$ & & & 4 & 26 & 9 \\
\hline & LVX & & & 8 & 30 & 1 \\
\hline & CIP & & & $\begin{array}{ll}4 & 7 \\
\end{array}$ & 28 & \\
\hline & $\mathrm{EtBr}$ & & & $10 \quad 26$ & 3 & \\
\hline
\end{tabular}

The MIC value of a strain grown in the presence of reserpine was divided by the MIC of the same strain grown in the absence of reserpine. The number of isolates that showed an increase or decrease in MIC values is shown. BES = Besifloxacin; MXF = moxifloxacin; $\mathrm{GAT}=$ gatifloxacin LVX = levofloxacin; $\mathrm{CIP}=$ ciprofloxacin; $\mathrm{EtBr}=$ ethidium bromide.

acin in the presence of reserpine. In contrast, only 4 of the 39 fluoroquinolone-resistant strains (Groups 2-6) had 4 -fold lower ciprofloxacin MIC values in the presence of reserpine. The remaining strains in Groups 2-6 had unchanged MIC values (28/39) or showed only a 2 -fold decrease (7/39). A similar trend was observed for the control agent ethidium bromide, where all fluoroquinolone-susceptible isolates experienced a 4 - to 16 -fold decrease in ethidium bromide MIC values in the presence of reserpine; however, fluoroquinolone-resistant isolates experienced no change or no more than a 4 -fold decrease in MIC values.

Recent work by Shinabarger et al. [26] examined the effect of various efflux pump inhibitors (reserpine, CCCP, and sodium orthovanadate) as well as mutations in the nor $A$ and mepA efflux pump genes, on fluoroquinolone susceptibility in $S$. aureus. Results from that study were consistent with the results reported here (table 3), which suggest that efflux pumps do not play a major role in resistance to besifloxacin, moxifloxacin, gatifloxacin, and levofloxacin in S. aureus when compared to the effect of mutations in the genes encoding DNA gyrase and topoisomerase IV. Our results also show that, for ciprofloxacin 
and ethidium bromide, the contribution of efflux pumps was more pronounced in fluoroquinolone-susceptible than in fluoroquinolone-resistant isolates.

\section{Potential Effect of DNA Gyrase/Topoisomerase IV Mutations}

The proteins that constitute DNA gyrase and topoisomerase IV are similar to each other in their structure and function and share common sequence motifs. Among those, amino acids within the QRDR are frequently mutated in isolates with high levels of fluoroquinolone resistance $[5,11,12,21]$; these include Ser-84, Ser- 85 and Glu88 in GyrA, and Ser-80 and Glu-84 in ParC, all of which were found to be mutated in this study (online suppl. fig. S1). Work by Laponogov et al. [15] on the structure of topoisomerase IV from S. pneumoniae in complex with moxifloxacin and DNA indicates that these residues are located within the proteins' $\alpha 4$ helix, which was in close proximity to the R1-cyclopropane ring of the fluoroquinolone. The authors suggested that introduction of bulky side chains in the $\alpha 4$ helix, such as those found in Phe or Tyr, might protrude into the quinolone-binding pocket and allosterically interfere with drug binding [15]. However, work by Wohlkonig et al. [16] and by Bax et al. [17] suggests that this pocket is filled by an $\mathrm{Mg}^{2+}$ ion that is held in place by Ser- 84 and Glu- 88 residues of ParE and two oxygen atoms of the quinolone. Under these circumstances, the Phe or Tyr mutations would be expected to interfere with the binding of the $\mathrm{Mg}^{2+}$ ion and thereby diminish the affinity of the fluoroquinolone for the enzyme.

Asp-432, which is part of the QRDR of ParE, was found to be mutated to His or Asn in three isolates in our study. The data presented here suggest that the Asp$432 \rightarrow$ His mutation had a greater impact on resistance to moxifloxacin, gatifloxacin, and levofloxacin than the Asp-432 $\rightarrow$ Asn mutation. Other authors [24, 25] reported Asp-432 $\rightarrow$ Gly and Asp-432 $\rightarrow$ Val mutations in ParE, which suggests that the loss of aspartate's acidic side chain, rather than allosteric hindrance, might be the main factor contributing to resistance. Evidence for the importance of an acidic residue in position 432 in supporting the fluoroquinolone-protein interaction comes from work done on the topoisomerase IV from Acinetobacter baumannii. The acidic side chain of the corresponding Asp-397 of ParE is in close proximity to the basic side chain of Arg-418, which itself is located next to the R7 substituent of moxifloxacin [16]. Depending on the chemical structure of the fluoroquinolone, mutations in these two residues can have different effects on quino- lone resistance as shown by Yoshida et al. [27]. In the present study, the MIC values of besifloxacin and ciprofloxacin did not differ between strains with Asp-432 $\rightarrow$ His and those with Asp-432 $\rightarrow$ Asn mutations, potentially because the smaller $\mathrm{R} 8$ residues in these two drugs $(8-\mathrm{Cl}$ in besifloxacin, 8-H in ciprofloxacin) allow for more flexibility of the large R7 groups. While Asp-432 $\rightarrow$ Asn, Asp$432 \rightarrow$ Gly, and Asp-432 $\rightarrow$ Val mutations in ParE have been reported previously [22-25, 27, 28], the Asp-432 $\rightarrow$ His mutation reported here appears to be novel.

Our data also implicate a mutation outside the QRDR of ParE, Pro-585 $\rightarrow$ Ser, in fluoroquinolone resistance, which was especially pronounced in the case of levofloxacin and ciprofloxacin. This residue is located within the conserved Toprim domain, which is involved in magnesium ion coordination for the cleavage-religation reaction [29]. However, the Pro-585 residue itself does not seem to be highly conserved since the corresponding amino acid in S. pneumoniae is an alanine (Ala-588). In the topoisomerase IV-DNA-moxifloxacin complex, Ala588 is located on the surface of ParE and in proximity to Asn-104 of ParC [15]. Support for a potential role of Pro$585 \rightarrow$ Ser in fluoroquinolone resistance comes from an investigation of 98 clinical S. aureus isolates from Korea, which identified a strain with mutations in GyrA (Ser$84 \rightarrow$ Leu), ParC (Ser-80 $\rightarrow$ Phe), and ParE (Pro-585 $\rightarrow$ Ser) that had higher MIC values for ciprofloxacin, sparfloxacin, and trovafloxacin than a strain that lacked the ParE (Pro-585 $\rightarrow$ Ser) mutation [25].

\section{Conclusions}

This study was conducted to gain further insights into the differential impact of mutations in DNA gyrase and topoisomerase IV on MIC values for besifloxacin and older fluoroquinolones. Therefore, this study focused on ciprofloxacin-resistant isolates and ciprofloxacin-susceptible comparators, while strains with intermediate- or low-level resistance were not included, which is the most probable reason why strains with single mutations in DNA gyrase or topoisomerase IV were not observed.

Since besifloxacin is a novel fluoroquinolone that has been approved for ophthalmic use, our focus was on $S$. aureus isolates from patients with ocular infections to determine which mutations are present in a clinically relevant setting. In the process, two new or unusual mutations were identified. Since the clinical isolates were not of the same genetic background, it is possible that other, as of yet unidentified mechanisms, could have contrib- 
uted to fluoroquinolone resistance. Efflux pumps and plasmid-encoded resistance genes, such as the qnr genes, $a a c\left(6^{\prime}\right)-I b-c r$ and $q e p A$, have been shown to contribute to resistance in Gram-negative bacteria [30]. In Gram-positive bacteria, only efflux pumps have been shown so far to augment fluoroquinolone resistance. The data presented here and by Shinabarger et al. [26] show that in S. aureus, the effect of efflux pumps was modest overall and more pronounced for ciprofloxacin than for the other fluoroquinolones. To our knowledge, all S. aureus isolates with clinically relevant levels of fluoroquinolone resistance contain mutations in the genes encoding DNA gyrase and/or topoisomerase IV, while they may or may not contain additional mutations affecting efflux pumps. Therefore, while we cannot rule out the contribution of other resistance mechanisms, mutations in gyrA and parC, and to a lesser extent $\operatorname{gyr} B$ and parE, still appear to be the primary fluoroquinolone resistance determinants in S. aureus. Future studies with isogenic mutants will serve to better elucidate the precise contribution of these mutations to fluoroquinolone resistance. In addition, hypotheses regarding the structure-function relationship between fluoroquinolones and their mutated target proteins serve as starting points for experiments that will serve to increase our knowledge of important drug attributes and resistance development. It will be of particular interest to better determine interactions of specific ParE alleles with the R7 and R8 substituents of various fluoroquinolones.

Overall, the data presented here confirm that besifloxacin is less affected by mutations that cause an increase in resistance to other fluoroquinolones. A comparison of the modal MIC values of susceptible isolates (Group 1) with those of the most resistant strains (Group 6) shows a 1,024- to 2,048-fold increase for moxifloxacin, gatifloxacin, ciprofloxacin, and levofloxacin. By comparison, the difference in modal MIC values between fluoroquinolone-susceptible and fluoroquinolone-resistant isolates was only 128 -fold for besifloxacin.

The higher potency of besifloxacin compared to the other fluoroquinolones suggests that the drug's unique combination of a 7-azepinyl ring and an 8-chloro-substituent results in unique interactions with DNA gyrase and topoisomerase IV. This conclusion is consistent with biochemical studies that show a higher affinity of besifloxacin for both enzymes than comparator fluoroquinolones [14].

\section{Acknowledgment}

This study was supported by an unrestricted grant from Bausch \& Lomb, Inc., Rochester, N.Y., USA.

\section{References}

1 Karpecki P, DePaolis M, Hunter JA, White EM, Rigel L, Brunner LS, Usner DW, Paterno MR, Comstock TL: Besifloxacin ophthalmic suspension $0.6 \%$ in patients with bacterial conjunctivitis: a multicenter, prospective, randomized, double-masked, vehicle-controlled, 5-day efficacy and safety study. Clin Ther 2009;31:514-526.

- 2 McDonald MB, Protzko EE, Brunner LS, Morris TW, Haas W, Paterno MR, Comstock TL, Usner DW: Efficacy and safety of besifloxacin ophthalmic suspension $0.6 \%$ compared with moxifloxacin ophthalmic solution $0.5 \%$ for treating bacterial conjunctivitis. Ophthalmology 2009;116:1615-1623.

-3 Tepedino ME, Heller WH, Usner DW, Brunner LS, Morris TW, Haas W, Paterno MR, Comstock T: Phase III efficacy and safety study of besifloxacin ophthalmic suspension $0.6 \%$ in the treatment of bacterial conjunctivitis. Curr Med Res Opin 2009;25:11591169.
-4 Haas W, Pillar CP, Zurenko GE, Lee JC, Brunner LS, Morris TW: Besifloxacin, a novel fluoroquinolone, has broad-spectrum in vitro activity against aerobic and anaerobic bacteria. Antimicrob Agents Chemother 2009;53:3552-3560.

5 Hooper DC: Mechanisms of fluoroquinolone resistance. Drug Resist Updat 1999;2:38-55.

-6 Ferrero L, Cameron B, Manse B, Lagneaux D, Crouzet J, Famechon A, Blanche F: Cloning and primary structure of Staphylococcus aureus DNA topoisomerase IV: a primary target of fluoroquinolones. Mol Microbiol 1994;13:641-653.

7 German N, Wei P, Kaatz GW, Kerns RJ: Synthesis and evaluation of fluoroquinolone derivatives as substrate-based inhibitors of bacterial efflux pumps. Eur J Med Chem 2008;43:2453-2463.

8 Neyfakh AA, Borsch CM, Kaatz GW: Fluoroquinolone resistance protein NorA of Staphylococcus aureus is a multidrug efflux transporter. Antimicrob Agents Chemother 1993;37:128-129.
9 McAleese F, Petersen P, Ruzin A, Dunman PM, Murphy E, Projan SJ, Bradford PA: A novel MATE family efflux pump contributes to the reduced susceptibility of laboratoryderived Staphylococcus aureus mutants to tigecycline. Antimicrob Agents Chemother 2005;49:1865-1871.

10 Drlica K, Hooper DC: Mechanisms of quinolone action; in Hooper DC, Rubinstein E (eds): Quinolone Antimicrobial Agents. Washington, DC, ASM Press, 2003, pp 1940.

11 Hooper DC: Mechanisms of action of antimicrobials: focus on fluoroquinolones. Clin Infect Dis 2001;328(suppl 1):S9-S15.

12 Blondeau JM: Fluoroquinolones: mechanism of action, classification, and development of resistance. Surv Ophthalmol 2004; 49(suppl 2):S73-S78

13 Hesje CK, Sanfilippo CM, Haas W, Morris TW: Molecular epidemiology of methicillinresistant and methicillin-susceptible Staphylococcus aureus isolated from the eye. Curr Eye Res 2011;36:94-102. 
14 Cambau E, Matrat S, Pan XS, Roth Dit BR, Corbel C, Aubry A, Lascols C, Driot JY, Fisher LM: Target specificity of the new fluoroquinolone besifloxacin in Streptococcus pneumoniae, Staphylococcus aureus and Escherichia coli. J Antimicrob Chemother 2009;63:443-450.

15 Laponogov I, Sohi MK, Veselkov DA, Pan XS, Sawhney R, Thompson AW, McAuley KE, Fisher LM, Sanderson MR: Structural insight into the quinolone-DNA cleavage complex of type IIA topoisomerases. Nat Struct Mol Biol 2009; 16:667-669.

16 Wohlkonig A, Chan PF, Fosberry AP, Homes P, Huang J, Kranz M, Leydon VR, Miles TJ, Pearson ND, Perera RL, Shillings AJ, Gwynn MN, Bax BD: Structural basis of quinolone inhibition of type IIA topoisomerases and target-mediated resistance. Nat Struct Mol Biol 2010;17:1152-1153.

17 Bax BD, Chan PF, Eggleston DS, Fosberry A, Gentry DR, Gorrec F, Giordano I, Hann MM, Hennessy A, Hibbs M, Huang J, Jones E, Jones J, Brown KK, Lewis CJ, May EW, Saunders MR, Singh O, Spitzfaden CE, Shen C, Shillings A, Theobald AJ, Wohlkonig A, Pearson ND, Gwynn MN: Type IIA topoisomerase inhibition by a new class of antibacterial agents. Nature 2010;466:935-940.

18 Clinical and Laboratory Standards Institute: Performance Standards for Antimicrobial Susceptibility Testing; Twentieth Informational Supplement. CLSI document M100S20. Clinical and Laboratory Standards Institute, Wayne, PA, 2010.
19 Clinical and Laboratory Standards Institute: Methods for Dilution Antimicrobial Susceptibility Tests for Bacteria That Grow Aerobically; Approved Standard, Eighth Edition. CLSI document M7-A8. Clinical and Laboratory Standards Institute, Wayne, PA, 2009.

-20 Lu T, Zhao X, Li X, Drlica-Wagner A, Wang JY, Domagala J, Drlica K: Enhancement of fluoroquinolone activity by C-8 halogen and methoxy moieties: action against a gyrase resistance mutant of Mycobacterium smegmatis and a gyrase-topoisomerase IV double mutant of Staphylococcus aureus. Antimicrob Agents Chemother 2001;45:2703-2709.

21 Hooper DC: Fluoroquinolone resistance among Gram-positive cocci. Lancet Infect Dis 2002;2:530-538.

22 Tanaka M, Onodera Y, Uchida Y, Sato K: Quinolone resistance mutations in the GrlB protein of Staphylococcus aureus. Antimicrob Agents Chemother 1998;42:3044-3046.

23 Morosini MI, Loza E, del CR, Almaraz F, Baquero F, Canton R: Fluoroquinolone-resistant Streptococcus pneumoniae in Spain: activities of garenoxacin against clinical isolates including strains with altered topoisomerases. Antimicrob Agents Chemother 2003;47:2692-2695.

-24 Hannachi-M'Zali F, Ambler JE, Taylor CF, Hawkey PM: Examination of single and multiple mutations involved in resistance to quinolones in Staphylococcus aureus by a combination of PCR and denaturing high-performance liquid chromatography (DHPLC). J Antimicrob Chemother 2002;50:649-655.
25 Yoon EJ, Lee CY, Shim MJ, Min YH, Kwon AR, Lee J, Choi EC: Extended spectrum of quinolone resistance, even to a potential latter third-generation agent, as a result of a minimum of two GrlA and two GyrA alterations in quinolone-resistant Staphylococcus aureus. Chemotherapy 2010;56:153-157.

-26 Shinabarger DL, Zurenko GE, Hesje C, Sanfilippo CM, Morris TW, Haas W: Evaluation of the effect of bacterial efflux pumps on the antibacterial activity of the novel fluoroquinolone besifloxacin. J Chemother 2011;23: 80-86.

-27 Yoshida H, Bogaki M, Nakamura M, Yamanaka LM, Nakamura S: Quinolone resistance-determining region in the DNA gyrase gyrB gene of Escherichia coli. Antimicrob Agents Chemother 1991;35:1647-1650.

28 Heddle J, Maxwell A: Quinolone-binding pocket of DNA gyrase: role of GyrB. Antimicrob Agents Chemother 2002;46:1805-1815.

29 Noble CG, Maxwell A: The role of GyrB in the DNA cleavage-religation reaction of DNA gyrase: a proposed two metal-ion mechanism. J Mol Biol 2002;318:361-371.

30 Seo MR, Park YS, Pai H: Characteristics of plasmid-mediated quinolone resistance genes in extended-spectrum cephalosporinresistant isolates of Klebsiella pneumoniae and Escherichia coli in Korea. Chemotherapy 2010;56:46-53. 